\title{
openheart No-reflow phenomenon and comparison to the normal-flow population postprimary percutaneous coronary intervention for ST elevation myocardial infarction: case-control study (NORM PPCI)
}

\author{
Jennifer Ann Rossington (1) , ${ }^{1}$ Eirini Sol, ${ }^{2}$ Konstantina Masoura, ${ }^{3}$ \\ Konstantinos Aznaouridis, ${ }^{2}$ Raj Chelliah, ${ }^{4}$ Michael Cunnington, ${ }^{1}$ Benjamin Davison, ${ }^{4}$ \\ Joseph John, ${ }^{4}$ Richard Oliver, ${ }^{4}$ Angela Hoye ${ }^{5}$
}

\begin{abstract}
- Additional material is published online only. To view, please visit the journal online (http://dx.doi.org/10.1136/ openhrt-2019-001215).
\end{abstract}

To cite: Rossington JA, Sol E, Masoura K, et al. No-reflow phenomenon and comparison to the normal-flow population postprimary percutaneous coronary intervention for ST elevation myocardial infarction: case-control study (NORM PPCI). Open Heart 2020;7:e001215. doi:10.1136/ openhrt-2019-001215

Received 6 December 2019 Revised 3 April 2020 Accepted 13 April 2020
Check for updates

(C) Author(s) (or their employer(s)) 2020. Re-use permitted under CC BY-NC. No commercial re-use. See rights and permissions. Published by BMJ.

For numbered affiliations see end of article.

Correspondence to Dr Jennifer Ann Rossington; jar@doctors.org.uk

\section{ABSTRACT}

Introduction No-reflow (NR) phenomenon is

characterised by the failure of myocardial reperfusion despite the absence of mechanical coronary obstruction. NR negatively affects patient outcomes, emphasising the importance of prediction and management. The objective was to evaluate the incidence and independent predictors of NR in patients presenting with ST-elevation myocardial infarction (STEMI).

Methods This was a single-centre prospective casecontrol study. Cases were subjects who suffered NR, and the control comparators were those who did not. Clinical outcomes were documented. Salient variables relating to the patients and their presentation, history and angiographical findings were compared using oneway analysis of variance or $\chi^{2}$ test. Multiple regression determined the independent predictors, and a risk score was established based on the $\beta$ coefficient.

Results Of 173 consecutive patients, 24 (13.9\%) suffered from NR, with $46 \%$ occurring post stent implantation. Patients with NR had increased risk of in-hospital death $(\mathrm{OR} 7.0,95 \% \mathrm{Cl} 1.3$ to 36.7 , $\mathrm{p}=0.022$ ). From baseline variables available prior to percutaneous coronary intervention, the independent predictors of NR were increased lesion complexity, admission systolic hypertension, weight of $<78 \mathrm{~kg}$ and history of hypertension. Continuous data were transformed into best-fit binary variables, and a risk score was defined. Significant difference was demonstrated between the risk score of patients with NR $(4.1 \pm 1)$ compared with controls $(2.6 \pm 1)(p<0.001)$, and the risk score was considered a good test (area under the curve $=0.823$ ). A score of $\geq 4$ had $75 \%$ sensitivity and $76.5 \%$ specificity.

Conclusion Patients with NR have a higher rate of mortality following STEMI. Predictors of NR include lesion complexity, systolic hypertension and low weight. Further validation of this risk model is required.

\section{Key questions}

What is already known about this subject?

- No-reflow (NR) phenomenon is associated with poor clinical outcomes, and a number of independent predictors have been identified. Risk scores developed from these variables are of limited clinical use due to requirement of data not routinely available at the time of primary percutaneous coronary intervention.

What does this study add?

- Of patients with ST-elevation myocardial infarction (STEMI) in a contemporary UK population, $13.9 \%$ suffered from NR, and these patients demonstrated a sevenfold increased rate of in-hospital death Independent predictors of NR quantifiable prior to coronary intervention were increased lesion complexity, admission systolic hypertension, weight of $<78 \mathrm{~kg}$ and history of hypertension. These variables, within a statistical model, developed a risk score deemed to be a good test for predicting NR.

How might this impact on clinical practice?

- The risk score, following further validation, would have a role in prediction of high-risk patients, guiding management strategy aiming to prevent NR and to improve outcomes.

- The score could further have use as a research tool, identifying a high-risk population for exploration of interventions on NR, as randomisation of an unselected STEMI cohort has established minimal clinical impact on NR from current therapies.

\section{INTRODUCTION}

Urgentreperfusion has been the gold standard of care for ST-elevation myocardial infarction (STEMI) since the 1980s when thrombolysis was proven to significantly reduce all-cause mortality. ${ }^{1}$ In the 1990 s, this was challenged 
with superior outcomes in those managed with primary percutaneous coronary intervention (PPCI). ${ }^{2}$ However, not all patients treated with PPCI have successful reperfusion. In 1992, Ito $e t a l^{3}$ first described the phenomenon of 'no reflow' (NR) in humans with acute myocardial infarction, whereby perfusion is not re-established despite patency of the epicardial coronary artery. The incidence of NR quoted in the literature is highly variable, ranging from $5 \%$ to $65 \% \cdot{ }^{4-6}$ However, all studies have consistently demonstrated that NR has a negative impact on prognosis with larger infarct size, increased frequency of left ventricular (LV) dysfunction, cardiogenic shock, stroke and predisposition to arrhythmia. ${ }^{78}$

Given the importance of NR, a number of studies and registries have aimed to identify those at greatest risk, ${ }^{79}$ and non-validated risk scores have been developed. ${ }^{10} 11$ However, these scores are not clinically useful as they incorporate variables such as neutrophil/lymphocyte count, not commonly available at the time of intervention. There is a need for interventionists to be able to identify high-risk patients prior to PPCI, to enable a more aggressive pharmacotherapy regime ${ }^{12}$ and modification of the percutaneous coronary intervention (PCI) strategy ${ }^{13}$ in order to reduce the risk of NR. The aims of this study therefore were to evaluate the incidence of NR in consecutive patients with STEMI treated with contemporary PPCI and to identify the independent predictors of NR in order to develop a clinically usable risk score.

\section{METHODS}

This was an open single UK centre prospective casecontrol study. Hull University Teaching Hospitals NHS Trust provides a $24 / 7$ tertiary PPCI service to a population of 1.2 million. The overall cohort was defined as consecutive patients presenting with STEMI treated with PPCI. Cases were subjects who suffered NR at any stage of the procedure, and the control comparators were those who did not have evidence of NR. Clinical outcomes were documented in-hospital and at 30 days.

NR phenomenon was defined as ${ }^{5}$

- Angiographical evidence of reopening of the occluded coronary artery with no evidence of flowlimiting residual stenosis $(<50 \%)$, dissection, vessel spasm or thrombus burden.

- Angiographical documentation of thrombolysis in myocardial infarction (TIMI) flow grade $\leq$ II.

- A TIMI flow grade III with a myocardial blush grade 0 or I, at least $10 \mathrm{~min}$ after the end of the PPCI procedure.

The main inclusion criteria were patients $\geq 18$ years old presenting with STEMI (as defined in online supplementary material) appropriate for PPCI over a 6-month period between December 2015 and May 2016. If coronary intervention was not procedurally possible (eg, unable to wire the vessel) or the patient did not survive the index procedure, the subject was excluded. All patients were managed by the operators as clinically appropriate to optimise the final result.

When a participant could not be contacted at follow-up $(n=3)$, outcomes were available from the Myocardial Ischaemia National Audit Project database. Information was collected prospectively or from electronic records regarding patient demographics and baseline clinical characteristics, admission and procedural data, coronary angiographical findings and in-hospital investigations. Clinical outcomes in-hospital and at 30 days were recorded following patient contact. Major adverse cardiovascular event (MACE) was defined as the composite of cardiovascular death, myocardial infarction and stroke. Angiographical and echocardiography assessments were analysed offline by two investigators independently (JAR and ES). Quantitative coronary angiography (QCA) guidance/scale definitions were used to maximise consistency. Any discrepancies were further reviewed, and consensus was reached.

Continuous characteristics were expressed as mean and SD, and categorical data were expressed as numbers (percentages). Continuous data were analysed using oneway analysis of variance, and categorical characteristics were analysed with $\chi^{2}$ to assess for correlation with NR. Simple binary logistic regression models were used to observe any association between the correlated baseline clinical and angiographical factors with NR (reported as OR with 95\% CI). Multiple backward stepwise logistic regression methodology enabled identification of independent variables in the prediction of NR. Receiver operating characteristic (ROC) curve analysis allowed conversion of continuous variables into dichotomous data with optimised cut-offs identified. The final categorical model was assessed with multiple logistic regression, and a score was calculated based on the $\beta$ coefficient. Two-sided $p$ values of $<0.05$ were considered to indicate statistical significance, yet $\mathrm{p}<0.1$ was felt to require further assessment in the regression model. All analyses were undertaken on SPSS V.24.

The study was monitored in accordance with Hull and East Yorkshire Hospitals NHS Trust R\&D department's standard operating procedures to ensure compliance with International Conference for Harmonisation of Good Clinical Practice and the Research Governance Framework 2005. There was no public or patient involvement in the conduct of this study. Data were collected and retained in accordance with the Data Protection Act 1998. Strengthening the Reporting of Observational Studies in Epidemiology statement guidelines were used in the reporting of this study. ${ }^{14}$

\section{RESULTS}

The study enrolled 173 patients (68\% male) with a mean age of 63 years (range 34-91 years). NR phenomenon was reported in 24 cases $(13.9 \%)$ and occurred after predilation in $6(25 \%)$, post-thrombectomy in $1(4.2 \%)$, 
following stent implantation in $11(45.8 \%)$ and after stent postdilation in $6(25 \%)$.

The clinical characteristics of those developing NR were explored compared with the control group (those who did not develop NR) (table 1).

The former group was an older population with increased medical history of hypertension and presented with higher systolic blood pressures. Patients with NR had a delay across all recorded timings related to symptom onset and important clinical interventions, when compared with the patients who did not, though this failed to reach statistical significance.

Furthermore, table 1 details the results of investigations obtained following the PPCI. Patients with NR had a higher creatinine level $(\mathrm{p}=0.038)$ and a trend to a lower haemoglobin level $(\mathrm{p}=0.066)$. The population with NR had a significantly greater level of N-terminal pro-B-type natriuretic peptide (NT-proBNP) $(\mathrm{p}=0.047)$. In keeping with this, a numerical trend was evident for reduced $\mathrm{LV}$ function in the NR cohort; however, this did not reach statistical importance $(\mathrm{p}=0.502)$.

Analysis of the angiographical images demonstrated that the culprit vessel, location, length of the lesion or thrombus class did not influence the occurrence of NR (table 2). However, NR was related to increased lesion complexity $(\mathrm{p}=0.001)$. Baseline TIMI flow did not significantly differ between the cases and control patients; there was a highly significant reduction in final TIMI flow and myocardial blush grade $(\mathrm{p}<0.001)$. Patients demonstrating reduced end TIMI flow/blush grade not categorised as NR pertain to cases failing to meet defining criteria, such as presence of distal emboli or dissection. NR cases with normal end procedure TIMI flow/blush grade represent patients who responded to procedural intervention administered during the PPCI.

Patients with NR were more likely to be treated with predilation, and this was performed at higher inflation pressures than those without NR. There was a trend towards more stent postdilation. Patients with NR received a lower dose of unfractionated heparin; however, the activated clotting time results were not significantly different. Patients with NR were more likely to receive glycoprotein (GP) IIb/IIIa inhibitor therapy (table 3).

\section{Clinical outcomes}

The clinical outcomes are shown in table 4. Patients with NR had significantly worse outcome than those without NR. At 30 days, patients with NR had a higher rate of MACE (16.7\% vs 5.4\%; OR 3.5, 95\% CI 1.0 to $12.9, \mathrm{p}=0.05)$, driven by a significantly higher in-hospital mortality $(12.5 \%$ vs $2.0 \%, \mathrm{p}=0.009)$.

\section{Predictors of NO reflow}

All characteristics with NR correlation ( $p$ value $<0.1$ ) underwent univariate analysis, and this determined increasing age, higher systolic blood pressure, lower heparin dose, prolongation of time between $\mathrm{P}_{2} \mathrm{Y}_{12}$ administration and arterial opening (balloon time), and
Table 1 Baseline characteristics and admission investigations of patients presenting with ST-elevation myocardial infarction comparing the NR group with the control group

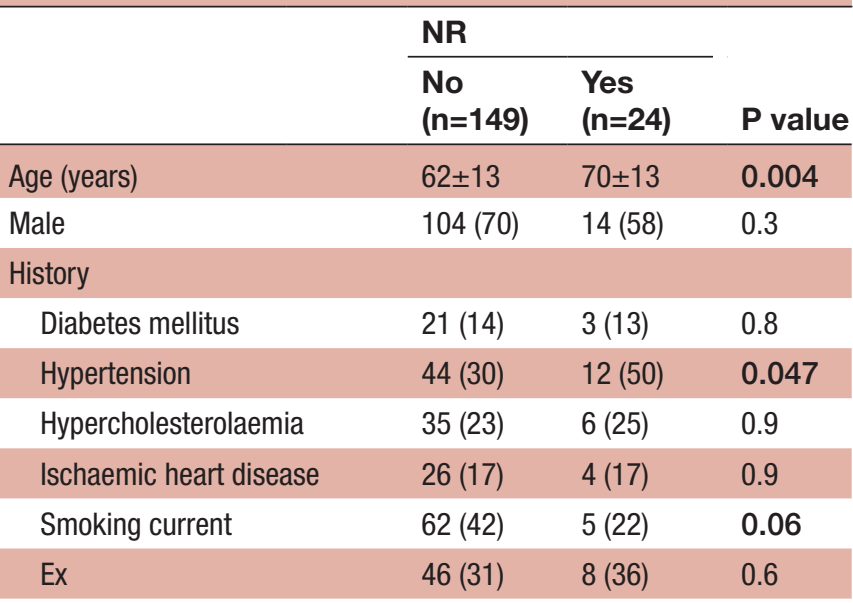

Examination on admission

\begin{tabular}{|llll} 
Weight (kg) & $85 \pm 20$ & $77 \pm 14$ & 0.087 \\
\hline Heart rate (beats/min) & $75 \pm 19$ & $78 \pm 20$ & 0.5 \\
$\begin{array}{l}\text { Systolic blood pressure (mm } \\
\text { Hg) }\end{array}$ & $138 \pm 28$ & $151 \pm 30$ & 0.03 \\
$\begin{array}{l}\text { Diastolic blood pressure (mm } \\
\text { Hg) }\end{array}$ & $80 \pm 16$ & $80 \pm 18$ & 0.9 \\
\hline Blood glucose & $8.0 \pm 3.3$ & $8.6 \pm 3.6$ & 0.4 \\
\hline
\end{tabular}

Killip class

\begin{tabular}{|c|c|c|c|c|}
\hline \multicolumn{2}{|l|}{1} & $118(79)$ & $15(63)$ & 0.056 \\
\hline \multicolumn{2}{|l|}{$\|$} & $25(17)$ & $7(29)$ & \\
\hline \multicolumn{2}{|l|}{ III } & $3(2)$ & $0(0)$ & \\
\hline \multicolumn{2}{|l|}{ IV } & $3(2)$ & $2(8)$ & \\
\hline \multicolumn{5}{|c|}{ Medication use prior to admission } \\
\hline \multicolumn{2}{|l|}{ Aspirin } & $25(17)$ & $4(17)$ & 1.0 \\
\hline \multicolumn{2}{|c|}{ Dual antiplatelet therapy } & $2(1)$ & $0(0)$ & 0.6 \\
\hline \multicolumn{2}{|c|}{ Anticoagulation warfarin } & $7(5)$ & $1(4)$ & 0.9 \\
\hline \multicolumn{2}{|l|}{ DOAC } & $1(1)$ & $1(4)$ & 0.1 \\
\hline \multicolumn{2}{|l|}{ Statin } & $42(28)$ & $8(33)$ & 0.6 \\
\hline \multicolumn{5}{|l|}{ Time to treatment } \\
\hline \multicolumn{2}{|c|}{ Symptoms to door time (min) } & $511 \pm 915$ & $681 \pm 1185$ & 0.4 \\
\hline \multicolumn{2}{|c|}{ Symptoms to balloon time (min) } & $543 \pm 918$ & $720 \pm 1195$ & 0.4 \\
\hline \multicolumn{2}{|c|}{ Door to balloon time (min) } & $32 \pm 14$ & $39 \pm 41$ & 0.1 \\
\hline \multicolumn{2}{|c|}{ Symptoms to aspirin time (min) } & $435 \pm 941$ & $628 \pm 1268$ & 0.4 \\
\hline \multicolumn{2}{|c|}{$\begin{array}{l}\text { Symptoms to } \mathrm{P}_{2} \mathrm{Y}_{12} \text { antagonist } \\
\text { (min) }\end{array}$} & $510 \pm 923$ & $656 \pm 1205$ & 0.5 \\
\hline \multicolumn{5}{|c|}{$\begin{array}{cl}\text { Inpatient investigations } & \begin{array}{l}\text { Normal } \\
\text { range }\end{array}\end{array}$} \\
\hline Haemoglobin $(g / L)$ & $\begin{array}{l}(135- \\
175)\end{array}$ & $142 \pm 18$ & $135 \pm 16$ & 0.066 \\
\hline Neutrophil $\left(\times 10^{9} / \mathrm{L}\right)$ & $(2.0-7.7)$ & $11.1 \pm 11.5$ & $11.5 \pm 4.1$ & 0.8 \\
\hline Platelet $\left(\times 10^{9} / \mathrm{L}\right)$ & $\begin{array}{l}(150- \\
400)\end{array}$ & $248 \pm 95$ & $216 \pm 73$ & 0.1 \\
\hline
\end{tabular}

Continued 
Table 1 Continued

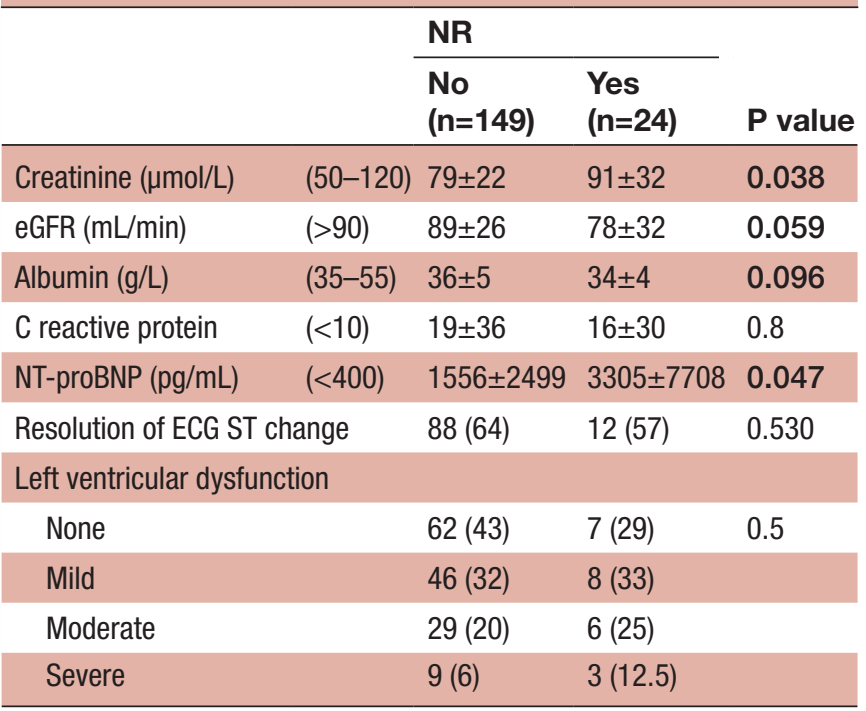

Continuous variables are expressed as mean \pm SD with correlation investigated with one-way analysis of variance. Categorical variables are expressed as number (percentage), with correlation investigated with $\chi^{2}$ test. $\mathrm{P}<0.05$ was deemed significant; however, $p<0.1$ (bold) suggested further analysis was required.

DOAC, direct-acting oral anticoagulant; eGFR, estimated glomerular filtration rate; NR, no reflow; NT-proBNP, N-terminal pro-B-type natriuretic peptide.

angiographical classification of the lesion to be significant predictors of NR (table 5).

A prediction model was considered containing all variables deemed statistically important and could be quantified preintervention (table 6) (age, lesion classification, systolic blood pressure, hypertension and non-smoker). In addition, symptoms to PCI time and admission glucose were trialled in the model, as both had been judged important in established risk models, ${ }^{10}{ }^{15}$ yet neither strengthened the model. History of hypertension, lesion classification, systolic blood pressure on admission and patient weight were found to be the independent predictors of NR.

\section{Risk score}

To enable risk score analysis, the continuous variables were transformed into binary outcomes. Systolic blood pressure of $\geq 138 \mathrm{~mm} \mathrm{Hg}$ (area under the curve (AUC) 0.626 ; $95 \%$ CI 0.507 to $0.744, \mathrm{p}=0.049$ ) had a $66.7 \%$ sensitivity and $49.7 \%$ specificity for NR prediction. Weight of $<78 \mathrm{~kg}$ (AUC $0.618 ; 95 \%$ CI 0.490 to $0.746, \mathrm{p}=0.088$ ) conferred $55 \%$ sensitivity and $67.9 \%$ specificity for NR. Following reinterpretation of these measurements, the final model was found to be of good fit (HosmerLemeshow 2.274, $\mathrm{p}=0.943$ ) and a significant predictor of NR phenomenon $\left(\chi^{2} 28.6, \mathrm{p}<0.001\right)$. Approximately $31.3 \%$ variation in NR outcome can be explained by the grouping of the characteristics using Nagelkerke pseudo $\mathrm{R}^{2}$ value (table 7 ).

There was a significant difference between the risk score values of patients who suffered from NR $(4.1 \pm 1)$
Table 2 Angiographical and procedural characteristics of patients presenting with ST-elevation myocardial infarction comparing the NR group with the control group

\begin{tabular}{|c|c|c|c|}
\hline & \multicolumn{2}{|l|}{ NR } & \multirow[b]{2}{*}{$P$ value } \\
\hline & No $(n=149)$ & Yes ( $n=24)$ & \\
\hline $\begin{array}{l}\text { Presence of multivessel } \\
\text { disease }\end{array}$ & $95(64)$ & $20(83)$ & 0.059 \\
\hline \multicolumn{4}{|l|}{ Culprit vessel } \\
\hline LAD & $52(35)$ & $7(29)$ & 0.8 \\
\hline $\mathrm{RCA}$ & $72(48)$ & $14(58)$ & \\
\hline LCx & $15(10)$ & $2(8)$ & \\
\hline Other & $10(7)$ & $1(4)$ & \\
\hline $\begin{array}{l}\text { Reference vessel diameter } \\
(\mathrm{mm})\end{array}$ & $3.0 \pm 0.6$ & $3.0 \pm 0.5$ & 1.0 \\
\hline Lesion length (mm) & $15.2 \pm 10.3$ & $18.3 \pm 7.5$ & 0.2 \\
\hline \multicolumn{4}{|l|}{ Lesion complexity } \\
\hline A & 0 & 0 & 0.001 \\
\hline B1 & $48(32)$ & $1(4)$ & \\
\hline B2 & $85(57)$ & $15(63)$ & \\
\hline C & $16(11)$ & $8(33)$ & \\
\hline
\end{tabular}

Thrombus class

\begin{tabular}{|c|c|c|c|}
\hline 0 & $3(2)$ & 0 & 0.2 \\
\hline 1 & $7(5)$ & 0 & \\
\hline 2 & $2(1)$ & $1(4)$ & \\
\hline 3 & $13(9)$ & 0 & \\
\hline 4 & $17(11)$ & $3(13)$ & \\
\hline 5 & $107(72)$ & $20(83)$ & \\
\hline \multicolumn{4}{|c|}{ Initial TIMI flow } \\
\hline 0 & $105(71)$ & $20(83)$ & 0.4 \\
\hline 1 & $16(11)$ & $1(4)$ & \\
\hline 2 & $18(12)$ & $1(4)$ & \\
\hline 3 & $10(7)$ & $2(8)$ & \\
\hline \multicolumn{4}{|c|}{ Collaterals } \\
\hline No & $82(55)$ & $9(38)$ & 0.104 \\
\hline Yes & $66(45)$ & $15(62)$ & \\
\hline \multicolumn{4}{|c|}{ Final TIMI flow } \\
\hline 0 & 0 & $2(8)$ & $<0.001$ \\
\hline 1 & $4(3)$ & $5(21)$ & \\
\hline 2 & $11(7)$ & $15(63)$ & \\
\hline 3 & $134(90)$ & $2(8)$ & \\
\hline \multicolumn{4}{|c|}{ Final myocardial blush grade } \\
\hline 0 & $3(2)$ & $8(33)$ & $<0.001$ \\
\hline 1 & $5(3)$ & $7(29)$ & \\
\hline 2 & $9(6)$ & $8(33)$ & \\
\hline 3 & $128(88)$ & $1(4)$ & \\
\hline
\end{tabular}

Continuous variables are expressed as mean \pm SD with correlation investigated with one-way analysis of variance. Categorical variables are expressed as number (percentage) with correlation investigated with $\chi^{2}$ test. $\mathrm{P}<0.05$ was deemed significant; however, $p<0.1$ (bold) suggested further analysis was required. LAD, left anterior descending; LCx, circumflex; NR, no reflow; $\mathrm{RCA}$, right coronary artery; TIMI, thrombolysis in myocardial infarction. 
Table 3 Procedural characteristics of patients presenting with ST-elevation myocardial infarction comparing those with no reflow to those without

\begin{tabular}{|c|c|c|c|}
\hline & \multicolumn{2}{|l|}{ No reflow } & \multirow[b]{2}{*}{ P value } \\
\hline & No $(n=149)$ & Yes $(n=24)$ & \\
\hline Heparin dose (units) & $8054 \pm 2347$ & $6818 \pm 2260$ & 0.022 \\
\hline Activated clotting time (s) & $290 \pm 82$ & $304 \pm 79$ & 0.549 \\
\hline $\begin{array}{l}\text { Glycoprotein Ilb/llla inhibitor } \\
\text { use }\end{array}$ & $33(22)$ & $6(25)$ & 0.784 \\
\hline Predilation performed & $103(70)$ & $24(100)$ & 0.002 \\
\hline $\begin{array}{l}\text { Predilation balloon } \\
\text { inflation pressure (atm) }\end{array}$ & $12 \pm 3$ & $14 \pm 4$ & 0.047 \\
\hline $\begin{array}{l}\text { Predilation balloon } \\
\text { diameter }(\mathrm{mm})\end{array}$ & $2.5 \pm 0.5$ & $2.5 \pm 0.4$ & 0.848 \\
\hline Stent inserted & $140(96)$ & $24(100)$ & 0.312 \\
\hline $\begin{array}{l}\text { Stent inflation pressure } \\
\text { (atm) }\end{array}$ & $15 \pm 2$ & $15 \pm 3$ & 0.988 \\
\hline Stent diameter (mm) & $3.3 \pm 0.5$ & $3.3 \pm 0.7$ & 0.527 \\
\hline Postdilation performed & $55(38)$ & $13(54)$ & 0.126 \\
\hline $\begin{array}{l}\text { Postdilation balloon } \\
\text { inflation pressure (atm) }\end{array}$ & $16 \pm 4$ & $17 \pm 4$ & 0.334 \\
\hline $\begin{array}{l}\text { Postdilation balloon } \\
\text { maximal diameter (mm) }\end{array}$ & $3.6 \pm 0.5$ & $3.7 \pm 0.6$ & 0.559 \\
\hline Thrombectomy use & $60(41)$ & $8(33)$ & 0.472 \\
\hline Screening time & $12.3 \pm 7.4$ & $14.5 \pm 11.7$ & 0.233 \\
\hline Radiation exposure (DAP) & $5553 \pm 3427$ & $5618 \pm 2940$ & 0.930 \\
\hline
\end{tabular}

Continuous variables are expressed as mean $\pm S D$ with correlation investigated with one-way analysis of variance. Categorical variables are expressed as number (percentage) with correlation investigated with $\chi^{2}$ test. $\mathrm{P}<0.05$ was deemed significant; however, $\mathrm{p}<0.1$ (bold) suggested further analysis was required.

DAP, dose area product.

compared with those who did not $(2.6 \pm 1)(\mathrm{p}<0.001)$, and the risk score was considered a good test (AUC 0.823; $95 \%$ CI 0.723 to $0.923, \mathrm{p}<0.001$ ) (figure 1 ). In depth review of the ROC curve stated a score of $\geq 3$ had $90 \%$ sensitivity and $49.8 \%$ specificity $(3 / 67,7.1 \%$; number of $\mathrm{NR} /$ total population (\%)), compared with $\geq 4$ with $75 \%$
Table 5 ORs for characteristics demonstrating correlation to no reflow

\begin{tabular}{|c|c|c|c|}
\hline & OR & $95 \% \mathrm{Cl}$ & $P$ value \\
\hline Age & 1.05 & 1.02 to 1.09 & 0.005 \\
\hline Weight & 0.97 & 0.95 to 1.0 & 0.081 \\
\hline NT-proBNP & 1.00 & 1.0 to 1.0 & 0.103 \\
\hline Haemoglobin & 0.98 & 0.95 to 1.0 & 0.068 \\
\hline Albumin & 0.93 & 0.85 to 1.01 & 0.1 \\
\hline eGFR & 0.98 & 0.97 to 1.0 & 0.061 \\
\hline $\begin{array}{l}\text { Heart failure (Killip } \\
\text { class) }\end{array}$ & 1.66 & 0.97 to 2.84 & 0.066 \\
\hline Systolic blood pressure & 1.02 & 1 to 1.03 & 0.03 \\
\hline $\begin{array}{l}\text { Predilation balloon } \\
\text { inflation pressure }\end{array}$ & 1.17 & 1 to 1.62 & 0.05 \\
\hline Aspirin to balloon time & 1.00 & 1 to 1.01 & 0.13 \\
\hline $\begin{array}{l}\mathrm{P}_{2} \mathrm{Y}_{12} \text { antagonist to } \\
\text { balloon time }\end{array}$ & 1.01 & 1 to 1.01 & 0.036 \\
\hline Smoker & 0.38 & 0.13 to 1.08 & 0.07 \\
\hline Hypertension & 2.39 & 1 to 5.72 & 0.051 \\
\hline $\begin{array}{l}\text { Intracoronary IIb/IIla } \\
\text { use }\end{array}$ & 6.59 & 0.88 to 49.22 & 0.066 \\
\hline Intravenous fluid use & 2.12 & 0.88 to 5.1 & 0.095 \\
\hline $\begin{array}{l}\text { Presence of multivessel } \\
\text { disease }\end{array}$ & 1.73 & 0.64 to 4.63 & 0.28 \\
\hline \multicolumn{4}{|l|}{ Classification } \\
\hline $\mathrm{B} 2$ versus B1 & 8.47 & 1.09 to 66.13 & 0.042 \\
\hline$C$ versus $B 1$ & 24.0 & 2.78 to 206.96 & 0.004 \\
\hline B2 versus $C$ & 0.35 & 0.13 to 0.97 & 0.043 \\
\hline
\end{tabular}

Figures show OR, $95 \% \mathrm{Cl}$ and subsequent $\mathrm{p}$ value. Killip class was entered as continuous variable. $\mathrm{P}<0.05$ was deemed significant; however, a $p<0.1$ (bold) was considered for the prediction model. eGFR, estimated glomerular filtration rate; NT-proBNP, N-terminal pro-B-type natriuretic peptide.

sensitivity and $76.5 \%$ specificity $(5 / 24,17.2 \%)$ and $\geq 5$ with $50 \%$ sensitivity and $94.1 \%$ specificity $(10 / 18,55 \%)$. Therefore, patients with a risk score of $<3$ have a low risk,

Table 4 In-hospital and 30-day clinical outcomes

\begin{tabular}{|c|c|c|c|c|c|c|}
\hline & \multicolumn{3}{|c|}{ In-hospital } & \multicolumn{3}{|l|}{30 days } \\
\hline & \multicolumn{2}{|c|}{ No reflow } & \multirow[b]{2}{*}{$P$ value } & \multicolumn{2}{|c|}{ No reflow } & \multirow{2}{*}{$\begin{array}{l}P \\
\text { value }\end{array}$} \\
\hline & No & Yes & & No & Yes & \\
\hline Cardiovascular death & $3(2)$ & $3(12.5)$ & 0.009 & $4(2.7)$ & $3(12.5)$ & 0.023 \\
\hline Myocardial infarction & $2(1.3)$ & 0 & 0.568 & $2(1.3)$ & $1(4.2)$ & 0.283 \\
\hline Cerebrovascular accident & $2(1.4)$ & 0 & 0.687 & $2(1.4)$ & 0 & 0.687 \\
\hline MACE & $7(4.7)$ & $3(12.5)$ & 0.129 & $8(5.4)$ & $4(16.7)$ & 0.043 \\
\hline Repeat revascularisation & $4(50)$ & 0 & 0.220 & 0 & 0 & \\
\hline Hospital readmission & - & - & - & $17(11.4)$ & $3(12.5)$ & 0.754 \\
\hline
\end{tabular}

Results quoted as number (percentage of relevant population), and correlation was investigated with $\chi^{2}$ test.

MACE, major adverse cardiovascular event. 


\begin{tabular}{|c|c|c|}
\hline $\begin{array}{l}\text { Precoronary } \\
\text { intervention }\end{array}$ & $\begin{array}{l}\text { Intraintervention / } \\
\text { postintervention }\end{array}$ & $\begin{array}{l}\text { Secondary to } \\
\text { NR? }\end{array}$ \\
\hline 1.Age. & 1.Heparin dose. & \\
\hline $\begin{array}{l}\text { 2.Lesion classification. } \\
\text { 3.Systolic blood } \\
\text { pressure. }\end{array}$ & $\begin{array}{l}\text { 2.Pre-dilation balloon } \\
\text { inflation pressure. }\end{array}$ & \\
\hline \multirow{2}{*}{$\begin{array}{l}\text { 4.P2Y } \mathrm{Y}_{12} \text { antagonist to } \\
\text { balloon time. }\end{array}$} & 3.eGFR. & 1.eGFR. \\
\hline & 4.Intracoronary IIb/llla. & $\begin{array}{l}\text { 2.Intracoronary } \\
\text { Ilb/Illa. }\end{array}$ \\
\hline 5.Hypertension. & & 3. Heart failure. \\
\hline 6.Non-smoker. & 5.Haemoglobin. & 4.Haemoglobin. \\
\hline 7. Weight. & 6. Intravenous fluids Use. & \\
\hline
\end{tabular}

Variables are divided into categories on whether information was available precoronary intervention or intraintervention/ postintervention, or if data may be influenced by the presence of NR rather than contributing to risk of NR. The order represents the statistical weighting, with 1 associated with the most significant $p$ value.

eGFR, estimated glomerular filtration rate; NR, no reflow.

and those with a score of $\geq 5$ have a high risk of developing NR.

\section{DISCUSSION}

NR phenomenon occurred in $13.9 \%$ of a contemporary population of patients presenting with STEMI, which was lower than anticipated. This inconsistency is partly dependent on the definition of NR and the sensitivity of the defining methodology. In particular, angiographical evaluation is relatively insensitive as compared with imaging with cardiac MRI or myocardial contrast echocardiography. ${ }^{16} 17$

Although the incidence was lower, NR remains an important condition with a fourfold increase in MACE at 30 days. This is in keeping with previously published data, ${ }^{4}$ and the impact is known to persist up to 5 years. ${ }^{5}$ These data support the need for a predictive risk score.

Table 7 Preinterventional risk score

\begin{tabular}{|c|c|c|c|c|c|}
\hline & OR & $95 \% \mathrm{Cl}$ & $\beta$ coefficient & $P$ value & $\begin{array}{l}\text { Risk } \\
\text { score }\end{array}$ \\
\hline \multicolumn{4}{|c|}{ Lesion classification } & 0.005 & \\
\hline B2 & 10.5 & 1.3 to 88.8 & 2.35 & 0.03 & 2 \\
\hline C & 37.7 & 3.9 to 369.2 & 3.63 & 0.002 & 3 \\
\hline $\mathrm{SBP} \geq 138 \mathrm{~mm} \mathrm{Hg}$ & 4.2 & 1.3 to 13.8 & 1.43 & 0.019 & 1 \\
\hline Weight $<78 \mathrm{~kg}$ & 3.3 & 1.1 to 9.8 & 1.20 & 0.03 & 1 \\
\hline $\begin{array}{l}\text { History of } \\
\text { hypertension }\end{array}$ & 3.2 & 1.1 to 9.1 & 1.15 & 0.034 & 1 \\
\hline
\end{tabular}

Exploration of categorical characteristics in a multiple logistic regression, entered in order or statistical importance. Risk score was calculate using the $\beta$ coefficient ratio compared to the lowest value. SBP, systolic blood pressure.

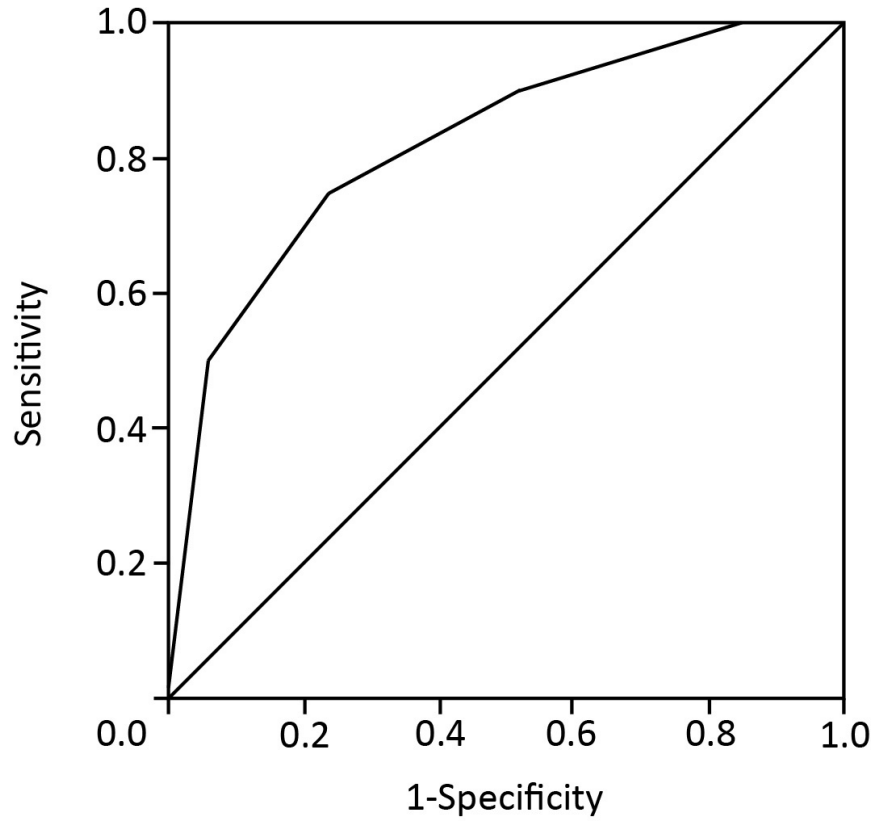

Figure 1 Receiver operating characteristic curve analysis for the no-reflow prediction model.

Understanding the pathophysiology may give further explanations for this reduction in events. NR has a multifactorial aetiology and broadly can be defined by four distinct groups: (1) distal atherothrombotic embolisation, (2) ischaemic injury, (3) reperfusion injury, and (4) susceptibility of coronary microcirculation to injury. Distal embolisation is a result of debris (thrombi, endothelial cells and lipid matrix) migrating downstream from the primary lesion, leading to microvascular obstruction and further injury. ${ }^{6}$ Ischaemic injury is relative to the duration of obstruction, secondary to the described thrombi, endothelial protrusions and extrinsic compression caused by oedematous change in the myocytes. Subsequently, platelets play a critical role in the development of the condition, and therapeutic practice switch in favour of newer $\mathrm{P}_{2} \mathrm{Y}_{12}$ inhibitors ${ }^{18}$ could be contributory to the lower incidence, as ticagrelor/ prasugrel are more potent antiplatelet agents compared with clopidogrel. ${ }^{19}{ }^{20}$ However, demonstration of NR reduction in randomised groups has not been seen. Our data also suggested a longer time elapse from symptoms to antiplatelet therapy in the NR group, although non-significant. Interestingly, a delay was seen across all timed variables for NR patents, implying prolonged obstruction/ischaemic injury. The findings in this cohort failed to reach statistical meaning, but larger studies support its importance. ${ }^{7}$ Therefore, another plausible contributing factor is UK geography, with relative short distances to medical contact and final PPCI therapy compared with some of our international counterparts.

Our model found lesion severity quantified by $\mathrm{B} 2 / \mathrm{C}$ classification had the highest predictive, value and its contribution to the risk score is a logical predictor. As described, the pathophysiology of NR is in part triggered by reperfusion injury secondary to inflammation and vasoconstriction induced by platelets, neutrophils and 
damaged endothelial cells, ${ }^{61}$ a response directly proportional to lesion severity/length. Indeed, NR has been previously linked with lesion severity and the degree of disease burden. ${ }^{722}$

NR is primarily a disease of the endothelium and microvasculature, both of which are negatively impacted by the presence of long-term systemic hypertension. ${ }^{23} 24$ Hence, hypertension results in a myocardial vasculature more susceptible to NR. It is conceivable that admission systolic hypertension is driven by either uncontrolled/ undiagnosed hypertension, or systemic adrenergic stress response induced by the STEMI presentation. The former is important to acknowledge as hypertensive control can improve coronary microvascular function. ${ }^{25}$ Myocardial ischaemia is known to stimulate catecholamine release and the renin-angiotensin system, resulting in systemic vasoconstriction proportional to the degree of ischaemia. ${ }^{26}$ Mirroring this is the vasoconstriction seen in the coronary vessels during infarction, ${ }^{27}$ and so systemic hypertension represents greater ischaemia and increased vasoconstriction, resulting in higher levels of ischaemic and perfusion injury contributing to NR.

Weight was also predictive with lower values representing an increase in risk. Patients with reduced body habitus may convey an older or potentially systemically unwell/frailer population. This is supported by the study demonstrating greater age, reduced estimated glomerular filtration rate and lower albumin levels in the NR cohort, although independently not predictive. Inversely, it may be more appropriate to consider increased weight being protective against NR. Although morbid obesity has been shown to convey a worse outcome for cardiovascular disease, overweight or obese states have been found to be protective. ${ }^{28}$ Adipocytes are linked with anti-inflammatory cascades and reduction in oxidative stress, ${ }^{29}$ which leads to consideration of 'healthy' overweight/obesity. Epicardial adipose tissue measurements, which has been shown to directly correlate to increased metabolic cardiovascular risk, ${ }^{30}$ were similar in both our cohorts suggesting a 'healthier' obese state in the control population.

We carefully explored previously highlighted independent predictors in other risk models. ${ }^{10}{ }^{15}$ Age and time from symptoms to therapy was significantly different between groups but not independently predictive. Interestingly, marked hyperglycaemia was infrequently seen in our group (blood glucose $\geq 12 \mathrm{mmol} / \mathrm{L}$ was $6.9 \%$ ), which may relate to its failure to contribute to the model. Differences found may relate to the population/ethnicity or clinical practice differences or, in case of timings, the marked variation time to intervention demonstrated.

\section{CONCLUSION}

No reflow phenomenon is an important condition seen during PPCI for STEMI. It conveys an increased risk of MACEs. Independent predictors of NR available prior to coronary intervention were increased lesion complexity, systolic hypertension on admission, weight of $<78 \mathrm{~kg}$ and previous history of hypertension. Further international multicentre validation of this risk model is required.

\section{Limitations}

The study was performed in a single UK centre with a small study population, which was almost solely Caucasian. This may limit its relevance to all populations. Furthermore, the diagnosis was angiography based rather than more sensitive methods, such as cardiac MRI or myocardial contrast echocardiography. However, this methodology was purposeful as it felt closer to real-world practice.

\section{Author affiliations}

${ }^{1}$ Department of Cardiology, Leeds Teaching Hospitals NHS Trust, Leeds, UK

${ }^{2} 1$ st Department of Cardiology, Athens Medical School, Hippokration Hospital,

Athens, Greece

${ }^{3}$ Department of Cardiology, Laiko General Hospital, Athens, Attica, Greece ${ }^{4}$ Cardiology, Castle Hill Hospital, Hull, UK

${ }^{5}$ Department of Academic Cardiology, Hull York Medical School Centre for Cardiovascular and Metabolic Research, Cottingham, UK

Contributors JAR: concept, designing, recruiting, collating, data analysis, statistics and writing; ES: recruiting, collating and data analysis; $\mathrm{AH}$ : concept, designing and writing: KM: data analysis; KA, MC, BD, RC, RO and JJ: recruiting and protocol.

Funding The authors have not declared a specific grant for this research from any funding agency in the public, commercial or not-for-profit sectors.

Competing interests None declared.

Patient consent for publication Not required.

Ethics approval Written consent was obtained in accordance with the Declaration of Helsinki for contact at 30 days. Patients who failed to survive to hospital discharge were included in the study without consent, as per approval from the Research Ethics Committee (Yorkshire and the Humber-Bradford Leeds (15/ YH/0360)), Site Specific Assessment and HEY Trust R\&D.

Provenance and peer review Not commissioned; externally peer reviewed.

Data availability statement All data relevant to the study are included in the article or uploaded as supplementary information. All data relevant to this study are included in the published text, tables, figures and supplemental material.

Open access This is an open access article distributed in accordance with the Creative Commons Attribution Non Commercial (CC BY-NC 4.0) license, which permits others to distribute, remix, adapt, build upon this work non-commercially, and license their derivative works on different terms, provided the original work is properly cited, appropriate credit is given, any changes made indicated, and the use is non-commercial. See: http://creativecommons.org/licenses/by-nc/4.0/.

ORCID iD

Jennifer Ann Rossington http://orcid.org/0000-0001-9946-6369

\section{REFERENCES}

1 Gruppo Italiano per lo Studio della Streptochinasi nell'Infarto Miocardico (GISSI). Effectiveness of intravenous thrombolytic treatment in acute myocardial infarction. Lancet 1986;1:397-402.

2 Grines CL, Browne KF, Marco J, et al. A comparison of immediate angioplasty with thrombolytic therapy for acute myocardial infarction. N Engl J Med 1993;328:673-9.

3 Ito H, Tomooka T, Sakai N, et al. Lack of myocardial perfusion immediately after successful thrombolysis. A predictor of poor recovery of left ventricular function in anterior myocardial infarction. Circulation 1992;85:1699-705.

4 Chan W, Stub D, Clark DJ, et al. Usefulness of transient and persistent no reflow to predict adverse clinical outcomes following percutaneous coronary intervention. Am J Cardiol 2012;109:478-85.

5 Ndrepepa G, Tiroch K, Fusaro M, et al. 5-Year prognostic value of no-reflow phenomenon after percutaneous coronary intervention in patients with acute myocardial infarction. J Am Coll Cardiol 2010;55:2383-9.

6 Niccoli G, Burzotta F, Galiuto L, et al. Myocardial no-reflow in humans. J Am Coll Cardiol 2009;54:281-92. 
7 Harrison RW, Aggarwal A, Ou F-shu, et al. Incidence and outcomes of no-reflow phenomenon during percutaneous coronary intervention among patients with acute myocardial infarction. Am J Cardiol 2013:111:178-84.

8 Ndrepepa G, Tiroch K, Keta D, et al. Predictive factors and impact of NO reflow after primary percutaneous coronary intervention in patients with acute myocardial infarction. Circulation 2010;3:27-33.

9 Jiecheng P, Ai-Ling W. Clinical significance of no-reflow in different stages of primary angioplasty among patients with acute myocardial infarctions. Perfusion 2016;31:1-7.

10 Dogan NB, Ozpelit E, Akdeniz S, et al. Simple clinical risk score for no-reflow prediction in patients undergoing primary percutaneous coronary intervention with acute STEMI. Pak J Med Sci 2015;31:576-81.

11 Wang J-W, Zhou Z-Q, Chen Y-D, et al. A risk score for no reflow in patients with ST-segment elevation myocardial infarction after primary percutaneous coronary intervention. Clin Cardiol 2015;38:208-15

12 Zhou S-S, Tian F, Chen Y-D, et al. Combination therapy reduces the incidence of no-reflow after primary per-cutaneous coronary intervention in patients with ST-segment elevation acute myocardial infarction. J Geriatr Cardiol 2015;12:1351-42.

13 Carrick D, Oldroyd KG, McEntegart M, et al. A randomized trial of deferred stenting versus immediate stenting to prevent NO- or SlowReflow in acute ST-segment elevation myocardial infarction (DEFERSTEMI). J Am Coll Cardiol 2014;63:2088-98.

14 Von EE, Altman DG, Egger M, et al. Strengthening the reporting of observational studies in epidemiology (STROBE) statement : guidelines for reporting observational studies. $\mathrm{Br}$ Med $\mathrm{J}$ 2007;335:806-8.

15 Wang $\mathrm{C}-\mathrm{H}$, Chen Y-D, Yang X-C, et al. A no-reflow prediction model in patients with ST-elevation acute myocardial infarction and primary drug-eluting stenting. Scand Cardiovasc $J$ 2011;45:98-104.

16 Durante A, Laricchia A, Benedetti G, et al. Identification of highrisk patients after ST-segment-elevation myocardial infarction: comparison between angiographic and magnetic resonance parameters. Circ Cardiovasc Imaging 2017;10:e005841.

17 Ramjane K, Han L, Jin C. The diagnosis and treatment of the noreflow phenomenon in patients with myocardial infarction undergoing percutaneous coronary intervention. Exp Clin Cardiol 2008;13:121-8 http://www.pubmedcentral.nih.gov/articlerender.fcgi?artid= 2586408\&tool=pmcentrez\&rendertype=abstract\%5Cnhttp://www. ncbi.nlm.nih.gov/pubmed/19343126
18 Task Force on the management of ST-segment elevation acute myocardial infarction of the European Society of Cardiology (ESC), Steg PG, James SK, et al. Esc guidelines for the management of acute myocardial infarction in patients presenting with ST-segment elevation. Eur Heart J 2012;33:2569-619.

19 Gurbel PA, Bliden KP, Butler K, et al. Response to ticagrelor in clopidogrel nonresponders and responders and effect of switching therapies: the respond study. Circulation 2010;121:1188-99.

20 Gremmel T, Eslam RB, Koppensteiner R, et al. Prasugrel reduces agonists' inducible platelet activation and leukocyte-platelet interaction more efficiently than clopidogrel. Cardiovasc Ther 2013;31:e40-5.

21 Galasso G, Schiekofer S, D'Anna C, et al. No-Reflow phenomenon: pathophysiology, diagnosis, prevention, and treatment. A review of the current literature and future perspectives. Angiology 2014;65:180-9

22 Magro M, Nauta ST, Simsek C, et al. Usefulness of the SYNTAX score to predict "no reflow" in patients treated with primary percutaneous coronary intervention for ST-segment elevation myocardial infarction. Am J Cardiol 2012;109:601-6.

23 Virdis A, Taddei S. Endothelial dysfunction in resistance arteries of hypertensive humans: old and new Conspirators. J Cardiovasc Pharmacol 2016;67:451-7.

24 Erdogan D, Yildirim I, Ciftci O, et al. Effects of normal blood pressure, prehypertension, and hypertension on coronary microvascular function. Circulation 2007:115:593-9.

25 Mizuno R, Fujimoto S, Saito Y, et al. Optimal antihypertensive level for improvement of coronary microvascular dysfunction: the lower, the better? Hypertension 2012;60:326-32.

26 Remme WJ, Kruyssen DA, Look MP, et al. Systemic and cardiac neuroendocrine activation and severity of myocardial ischemia in humans. J Am Coll Cardiol 1994;23:82-91.

27 Sahin M, Demir S, Kocabay G, et al. Coronary vessel diameters during and after primary percutaneous coronary artery intervention. Herz 2014;39:515-21.

28 Romero-Corral A, Montori VM, Somers VK, et al. Association of bodyweight with total mortality and with cardiovascular events in coronary artery disease: a systematic review of cohort studies. Lancet 2006;368:666-78.

29 Lim S, Quon MJ, Koh KK. Modulation of adiponectin as a potential therapeutic strategy. Atherosclerosis 2014;233:721-8.

30 lacobellis G, Corradi D, Sharma AM. Epicardial adipose tissue: anatomic, biomolecular and clinical relationships with the heart. Nat Clin Pract Cardiovasc Med 2005;2:536-43. 